\title{
Performance of neutral model analysis in a spatio- temporal series of macrobenthic replicates
}

\author{
I. Karakassis*, C. J. Smith, A. Eleftheriou \\ Institute of Marine Biology of Crete, PO Box 2214, GR-71003 Heraklion, Crete, Greece
}

\begin{abstract}
The macrofaunal composition of 240 samples from the continental shelf of Crete, Greece, taken at 4 different depths and in 6 different months of the year, were used in order to test the performance of neutral model analysis in comparison to more traditionally used diversity indices. It was found that neutral model analysis produces less repeatable results in comparison to most of the diversity indices. The deviation statistic $V$ was found to be negative in most of the samples $(88 \%)$ and significantly negative in $34 \%$ of these. However no other indication of disturbance was found at the community level as far as the species composition was concerned. The negative deviation from neutrality was found to be stronger in the samples taken from $100 \mathrm{~m}$ depth, negligible in the $70 \mathrm{~m}$ depth samples, and intermediate in the deeper ones (130 and $170 \mathrm{~m}$ depth). Sampling season was not consistently related to the deviation from neutrality. Sample size was found to affect significantly all the diversity indices, but only in the case of the $V$ statistic were the average values of the 24 data sets not correlated to the pooled sample values.
\end{abstract}

KEY WORDS: Neutral model analysis - Diversity Macrobenthos

\section{INTRODUCTION}

Neutral model analysis of community structure, introduced by Caswell (1976), has been discussed in several papers dealing with theoretical aspects of community structure (Hughes 1986, Loehle 1987, Cale et al. 1989, Turner 1989, Tokeshi 1993) and modelling of ecological processes (Turner et al. 1989, Clarke 1990, Capone \& Kushlan 1991, Cornell \& Lawton 1992, Armbruster et al. 1994). Both the method introduced and the findings in Caswell's paper (1976) are important since they seem to be able to provide evidence of strategic importance that could decide the outcome of the battle between the organismic and individualistic schools which has been going on since the early decades of this century (McIntosh 1995). However the application of this method to real community data has been relatively limited and principally concerns benthic marine ecology (Goldman \& Lambshead 1989).

\footnotetext{
·E-mail: jkarak@imbc.gr
}

One of the important conclusions of studies in which this model has been used is that the action of biological accommodation does not necessarily increase diversity, as has been considered in several other cases, but also decreases it (Caswell 1976, Rainer 1981).

The model has been used with macrofaunal data by Rainer (1981), Platt \& Lambshead (1985), Warwick et al. (1990) and Garcia \& Salzwedel (1991), all analysing assemblages from shallow depths (less than $20 \mathrm{~m}$ ), and by Warwick (1993), who examined the performance of the andysis on a well-defined pollution gradient in a deeper area (approximately 80 to $100 \mathrm{~m}$ ) at the Garroch Head sewage sludge dumping ground in Scotland. In most cases the number of samples analysed was small and the number of replicates was limited.

Neutral model analysis has promised to do more than any other diversity index, i.e. not only to summarize in a single value how diverse a community is (Tokeshi 1993) but also to measure the level of ecological disturbance. In this context disturbance has been defined as 'a process which occurs when any physical or biological agent acts to reduce population size, either by a direct biocidal action or by some indirect 
effect on population growth rates' (Platt \& Lambshead 1985). This method has been accepted with enthusiasm by some authors as 'an extremely sensitive and relatively sample-size independent method for analysing diversity' (Lambshead 1986), and as a useful tool for the analysis of ecological disturbance, both physical and biological (Lambshead \& Platt 1988). However, the methodology has also been generally criticized (Ugland \& Gray 1983).

Theoretical models are useful concepts of ecological phenomena; however, real data always present larger or smaller deviations from whatever a model has predicted. A practical criterion for the use of a diversity index in ecological and monitoring studies is its repeatability or the low variability within a series of replicates as well as its ability to detect deviation from 'normal' conditions. In the present paper 24 sets of macrofaunal samples (4 stations at depths from 70 to $160 \mathrm{~m}$, sampled during 6 different time periods), each consisting of 10 replicates, are examined using neutral model analysis, as well as other more traditionally used diversity indices in order to assess the consistency of each index in assigning similar values to the community regardless of the small-scale random variation.

\section{MATERIAL AND METHODS}

Six sampling cruises (in November 1989, January 1990, May 1990, July 1990, September 1990, and December 1990) were conducted with the RV 'Philia' in Heraklion Bay (Crete, Greece), visiting 4 stations (H5, H6, H7 and H8) located at 70, 100, 130 and $160 \mathrm{~m}$ depth respectively. Ten replicates were taken at each station in each sampling cruise, utilising a $0.1 \mathrm{~m}^{2}$ Smith-McIntyre grab, sieved through a $0.5 \mathrm{~mm}$ sieve and the fauna sorted and identified to species level. The substrate was uniformly silty and no obvious patchiness was found through the analyses of the environmental parameters in each station. Therefore it may be assumed that the replicates came from the same macrobenthic community.

For each of the 240 replicate samples a series of univariate values was calculated:

(1) Neutral model deviation statistic ( $V$ ) was calculated using the algorithm of Goldman \& Lambshead (1989) implemented in the PRIMER software package (developed in Plymouth Marine Laboratory, UK) on a 386 IBM computer

(2) Diversity indices commonly used in ecological studies: equitability $\left(J^{\prime}\right)$ after Pielou (1969), species richness $(d)$ according to Margalef (1958), information index $\left(H^{\prime}\right)$ using the Shannon-Wiener function (Shannon \& Weaver 1949), Simpson's (1949) index of diversity (D), the total species number in each sample (TSN), and a series of Hill's (1973) diversity measures $N_{1}, N_{10}$ : $N_{\infty}$. Hill's (1973) numbers are given by:

$$
N_{d}=\left(p_{1}^{d}+p_{2}^{a}+p_{3}^{d}+\ldots+p_{n}^{a}\right)^{1 / 1-d}
$$

where $N_{a}$ is the ath order of diversity; and $p_{n}$ is the proportional abundance of the $n$th species.

Repeatability analysis was performed according to Krebs (1989). This method provides a value ranging from 0 to 1.0 that shows how similar repeated measurements are on the same individual items. In this case the value of a (diversity or other) index in each of the 10 replicates was treated as a repeated measurement of a community parameter. Repeatability is given by the formula:

$$
R e p=\frac{S_{A}^{2}}{S_{E}^{2}+S_{A}^{2}}
$$

where $R e p$ is repeatability; $S_{A}^{2}$ is variance among groups (i.e. among sets of samples); $S_{E}^{2}$ is variance within groups (i.e. among replicates of the same set of samples).

Lower and upper confidence limits for $R e p\left(R_{I}\right.$ and $R_{U}$ respectively) were also calculated after Krebs (1989) for $95 \%$ probability.

\section{RESULTS}

The repeatability analysis results (Table 1) show the different performances of various indices. The total number of species (TSN) in a sample seems to be the more repeatable expression of the community diversity $($ Rep $=0.726)$. This also holds true for most of the indices based on species number such as $d_{1} N_{1}$ and $H^{\prime}$ while most of the equitability-influenced indices $(D, J$, $V$ ) are markedly less repeatable. This is due to the fact

Table 1. Performance of $V$ statistic and diversity indices in repeatability analysis. $J^{\prime}$ equitability; d: species richness; $H^{\prime}$ : Shannon-Wiener information index; $D$ : Simpson's index of diversity; TSN: total species number in each sample; $N_{1}, N_{10}$ $N_{\infty}$ : series of Hill's diversity measures; Rep: repeatability; $R_{L}$ $R_{U}$ lower and upper confidence limits for $R e p$ respectively

\begin{tabular}{|lccc|}
\hline Index & $R_{L}$ & $R e p$ & $R_{U}$ \\
\hline$V$ & 0.154 & 0.275 & 0.462 \\
$J^{\prime}$ & 0.178 & 0.304 & 0.494 \\
$D$ & 0.200 & 0.331 & 0.522 \\
$N_{\infty}$ & 0.201 & 0.332 & 0.523 \\
$N_{10}$ & 0.222 & 0.357 & 0.548 \\
$H^{\prime}$ & 0.469 & 0.611 & 0.764 \\
$N_{1}$ & 0.498 & 0.637 & 0.783 \\
$d$ & 0.537 & 0.671 & 0.807 \\
TSN & 0.602 & 0.726 & 0.844 \\
\hline
\end{tabular}


(a)

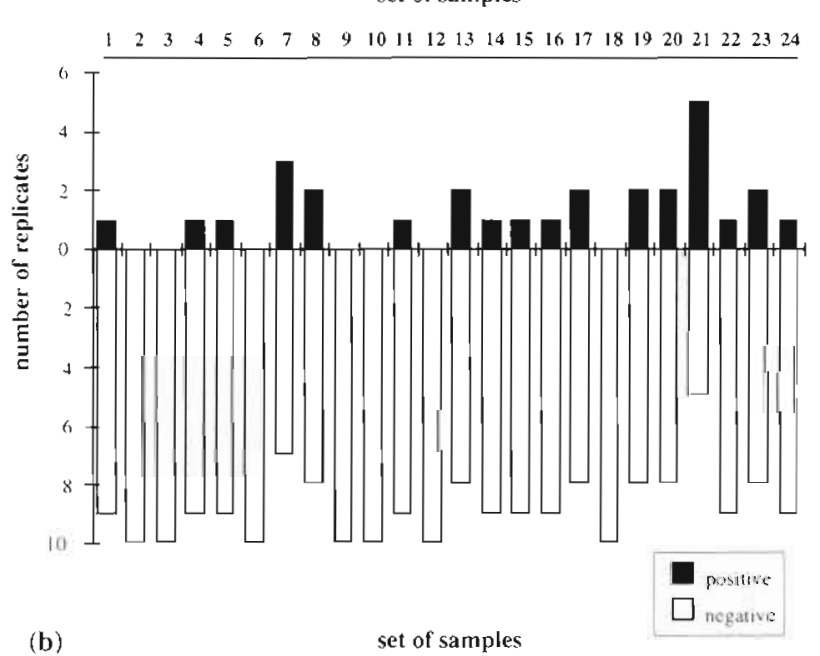

$\begin{array}{lllllllllllll}1 & 2 & 4 & 5 & 6 & 7 & 8 & 9 & 1011 & 1213 & 1415161718192021222324\end{array}$

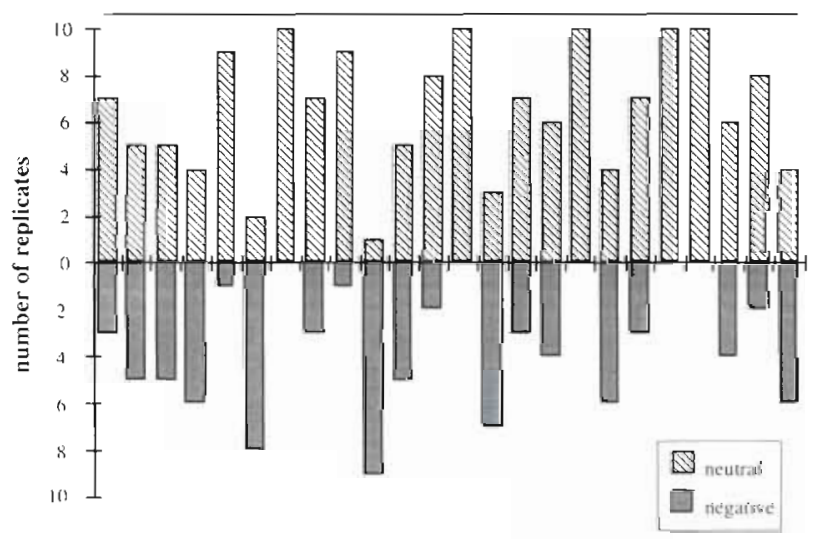

Fig. 1. Number of replicates in each data set presenting $V$ values: (a) positive or negative, (b) neutral or significantly negative

that the most dominant species in each sample present highly variable abundance severely influencing the latter category of indices. However it should be noted that the proportional cumulative abundance of the first pair of species in each sample never exceeded $35 \%$.

The number of replicates per sample set below or above the predictions of neutral model are shown in Fig. 1. In Fig. 1a negative $(V<0)$ and positive $(V>0)$ values are presented, while in Fig. $1 \mathrm{~b}$ only negative and neutral values are indicated. In the latter case the significance of the deviation was taken into account, i.e. only values $>+2$ and $<-2$ were considered as significantly deviating from neutrality (Warwick et al. 1990). This analysis gave no significantly positive deviation; still, $34 \%$ of the values were significantly lower than that predicted by the neutral model. This departure from neutrality, i.e. excessive dominance, has been considered by some authors as a symptom of disturbance (Rainer 1981, Warwick et al. 1990). In all the

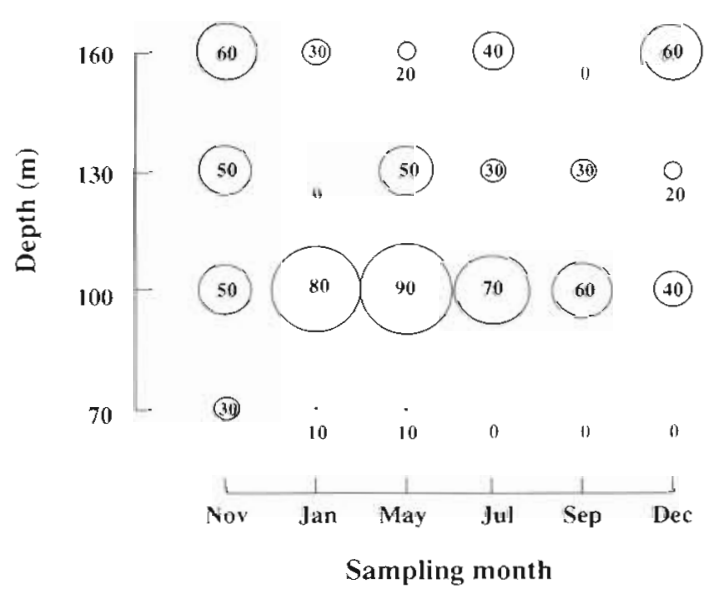

Fig. 2. Percentage of the samples (\%) presenting a $V$ statistics value significantly lower than neutrality. (Diameter of the circles is proportional to the respective percentage)

samples collected in the frame of the present study, including those that presented $V<-2$, no disturbance indicator species were found, nor any heavy recruitment, which could also produce excessive dominance.

In Fig. 2 the percentage of significantly negative $V$ values is presented in relation both to sampling month and depth. At the $100 \mathrm{~m}$ depth station the number of negative values was considerably high (39 out of 60). In the shallow stations of $70 \mathrm{~m}$ depth, where the variation of physical factors is more important and therefore where physical stress would be expected to be higher, almost all the samples produced $V$ values close to neutrality. In the deeper stations (i.e. at 130 and $160 \mathrm{~m}$ depth) where all the environmental conditions are fairly stable, approximately $1 / 3$ of the samples presented significantly negative $V$ values. No consistent pattern was found in relation to the season for the shallow station, while in November and May the majority of the deeper stations' samples was found to deviate significantly from neutrality.

In order to examine the aspect of 'sample size independence', the neutral model was applied to a 'supersample' where all 10 replicates of each set of samples were pooled. The resulting value, for each of the 24 sets of samples, was compared to the average value of the 10 replicates of the respective set through a paired $t$-test. The correlation coefficient $\left(R^{2}\right)$ between pooled and average values was also determined. The same analysis was also performed on 5 diversity indices $\left(J^{\prime}\right.$, $H^{\prime}, d, D$ and $N_{1}$ ). The differences in values between the pooled and the average for each data set are illustrated in Fig. 3, while the results of the statistical comparisons are presented in Table 2. In all cases there was a significant difference between pooled and average vaiues. The pooled samples presented lower equitability $\left(J^{\prime}\right)$, lower values for the Simpson index $(D)$ and lower 

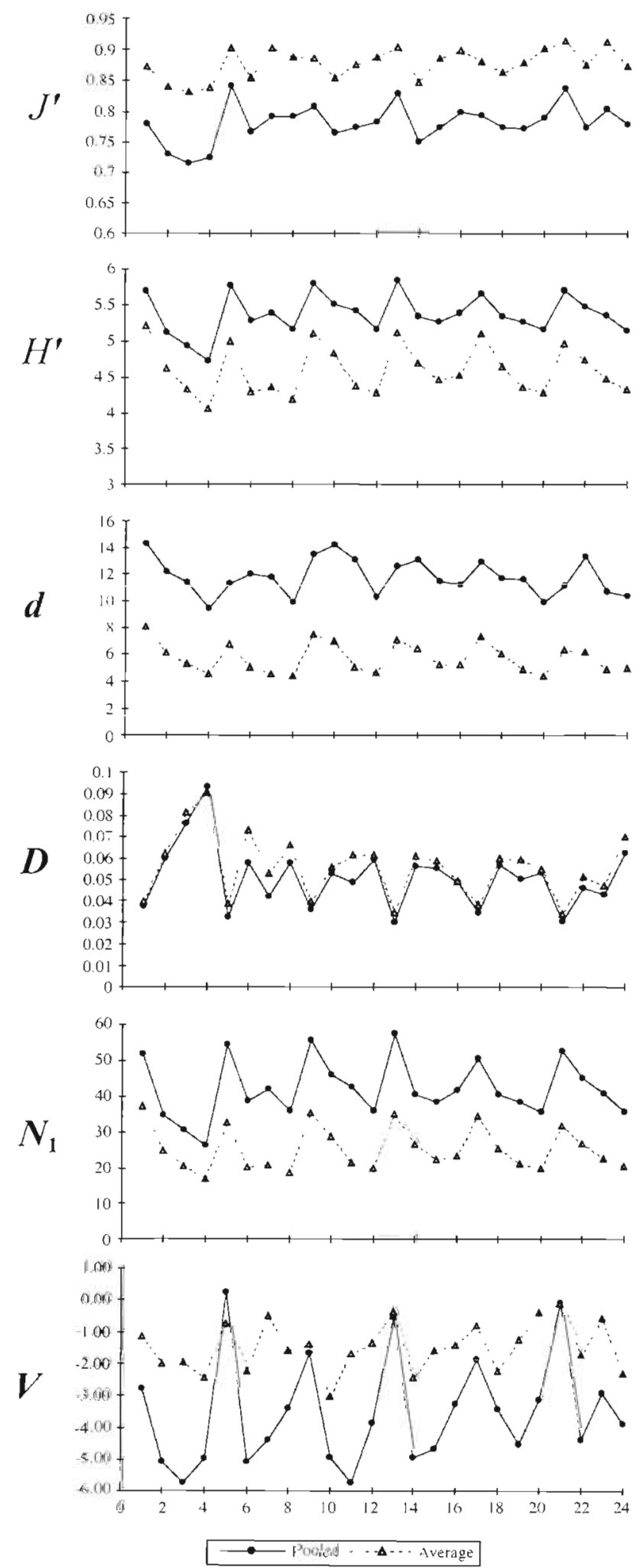

set of samples

Fig. 3. Values of indices obtained for each set of samples by (a) pooling all replicates and (b) averaging the values of the 10 replicates
Table 2. Correlation coefficient between the average value of the 10 replicates and the value for the pooled samples in the 24 sample sets

\begin{tabular}{|cc|}
\hline Index & $\mathrm{R}^{2}$ \\
\hline$D$ & 0.93 \\
$N_{1}$ & 0.82 \\
$J^{\prime}$ & 0.81 \\
$H^{\prime}$ & 0.78 \\
$d$ & 0.61 \\
$V$ & 0.48 \\
\hline
\end{tabular}

values for the $V$ statistic. On the other hand, species richness (d), $H^{\prime}$ and $N_{1}$ values were higher in the pooled samples and this may be attributed to the fact that the number of species plays a more important role in determining the value of these indices. However, apart from $V$ statistic, in all other cases the pooled and the average values were highly correlated $\left(R^{2}>0.6\right)$. It seems therefore that $V$ is not as 'sample size independent' as has been assumed so far. An additional problem arises when characterising the assemblage as 'significantly less diverse than neutral model prediction': if the average $V$ is taken into account, only $25 \%$ ( 6 out of 24) of the sample sets present a value significantly lower than zero, but in the case of the pooled samples, $79 \%$ (19 out of 24 ) seem to be significantly negative

The relative size of the species pool available $\left(R_{i}\right)$ from which immediate recolonization could be expected in a minimal area, such as that of a sampling quadrat, could be expressed by the ratio:

$$
R_{i}=\frac{S_{k}-s_{i}}{s_{i}}
$$

where $s_{j}$ is the species present in the $i$ th. quadrat and $S_{k}$ is the total number of species in the 10 replicates of the $k$ th set of samples.

For each set of samples the percent average $R_{i}$ is calculated after the formula:

$$
A R_{k}=100 \frac{1}{10} \sum_{i=1}^{10} R_{i}
$$

It could be expected that the larger the $A R_{k}$ the higher the probability for the individual patches of a set of samples to receive immigrants from the surrounding community which would increase the species richness. This simple ratio however does not take into account the number of individuals of the absent species and therefore the probability is only roughly estimated.

In Fig. 4 the neutral model $V$ statistic is plotted against $A R_{k}$ for all 24 sets of samples. It seems that relatively larger available species pools are consistently 


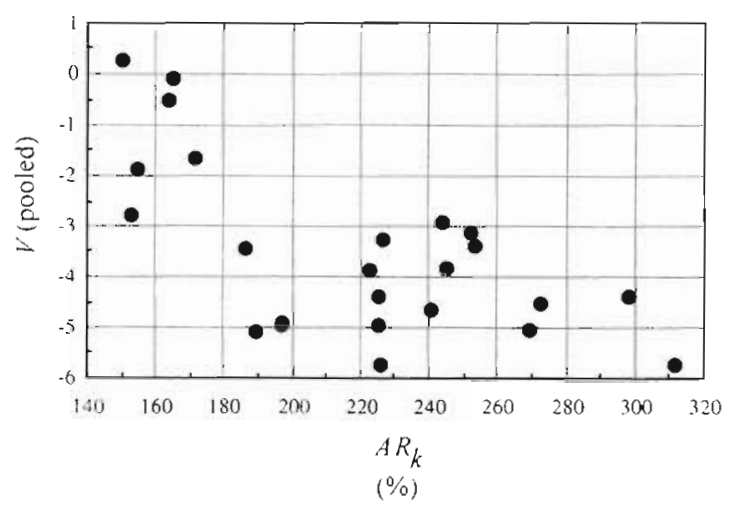

Fig. 4. $V$ statistic in relation to the average relative size of the species pool available for recolonization from adjacent patches

related to significant deviation from neutral model predictions, i.e. excessive dominance.

\section{DISCUSSION}

According to Caswell (1976) there are some important restrictions on the data to which the neutral model analysis can be applied, such as: (1) the data are assumed to consist of a random sample from a community that has been operating for a long time, (2) the data must consist of counts of discrete individuals and (3) the data cannot have been 'compressed' or 'expanded' (i.e. changing the sample size in artificial ways).

All the above-mentioned restrictions were kept in our data except (1) which is, as Caswell (1976) acknowledged, impossible to judge a priori. This restriction is in fact one of the main problems of the neutral model analysis since it renders the entire method an unfalsifiable one (i.e. any disagreement with the neutral model predictions could be attributed to this particular problem). However the communities used in this study have been monitored for the last $7 \mathrm{yr}$ with no visible changes. The area is also relatively offshore and free of major anthropogenic influences.

Lambshead \& Platt (1988) noted that in order to obtain meaningful results the sample size should not be too small because, since species can never be represented by less than 1 individual, species drop out as a sample is decreased in size. Although in the present paper none of the individual replicates had less than 33 individuals (and 234 had more than 50) it is reasonable to assume that the pooled samples better represent the parent community since the diversity potential in terms of species richness is a much closer approximation. In the latter case no sample had less than 563 individuals and 92 species.
Ugland \& Gray (1983) addressed the issue that it seems improbable that all examples should consistently be equal or below neutral model predictions. Caswell (1983) replied that in the examples he examined, $V$ was negative in only $28 \%$ of the cases. In the present study a large proportion of the individual replicate samples ( $88 \%$ ) produced negative $V$ values while $34 \%$ presented significantly lower values than those predicted by the neutral model $(V<-2)$. In the analysis of the pooled samples $79 \%$ (19 out of 24 ) were found to be significantly negative. In fact the negative values seem to be rather high, as Ugland \& Gray (1983) noticed, but it is also true that the samples which present the lowest values are those that could have been expected to be more diverse, as Caswell (1983) suggested.

Used in pollution studies, the neutral model analysis has produced conflicting results. Platt \& Lambshead (1985) found significant differences in the $V$ statistic for the Clyde Sea area (Scotland) assemblages of nematodes between contaminated and uncontaminated samples (the latter being less diverse than the former); this difference was attributed to pollution. In macrofaunal assemblages, however, they found a reduction in diversity in the polluted sites. Only 2 macrobenthic samples out of 16 presented in that paper were found to be significantly less diverse than the neutral model's prediction.

Smith \& Simpson (1992) found that the neutral model is a useful tool for detecting differences between samples from control and treatment (polluted) locations; it was at the former, however, where they obtained the lowest $V$ values.

Warwick et al. (1990), examining the macro- and meiofaunal communities from Bermuda Harbour, found that for the meiofauna, the $V$ statistic for all 6 stations analysed was close to neutrality while for the macrofauna, 2 values (out of 6 ) were significantly lower than the neutral model prediction, suggesting a severely disturbed condition.

Warwick (1993) used the neutral model in the analysis of macrobenthic data in an exhaustively studied sewage dumping site and stated that the poor performance of this statistic along such a well-defined pollution gradient does not augur well for its use in the pollution detection and monitoring context' while other diversity indices were able to detect changes in the community structure coinciding with the independent assessment of pollution parameters.

Lambshead \& Platt (1988) argued that physical disturbance and biological interactions such as predation may produce interchangeable results on a neutral model since disturbance is an efíect, not a causdive agent or process; in other words 'stress is defined by its effects'. However as Rapport et al. (1985) emphasized, 
what actually constitutes health in an ecosystem is not based on objective criteria but rather involves judgment in deciding which parameters are significant in the ecosystem's responses to stress.

The effects of severe environmental stress are usually obvious, whether judged by low diversity or by the presence of particular indicator species, but when the stress is relatively mild the measures of community structure may often be of limited usefulness (Rainer 1981). In the present study no obvious consequences of environmental stress were detected. On the contrary all samples presented rather high values in most of the diversity indices applied. However neutral model analysis revealed a considerable negative deviation in a large proportion of the samples which might be thought to indicate that the community is subjected to either physical or biological stress. Because the deviating samples are found in the deeper stations and only in a proportion of the replicates, it can be concluded that the stress in this case could only be of a biological nature and rather small in scale.

As Palmer (1994) noted, at least 120 hypotheses have been proposed to account for variation in species richness and/or diversity so that some authors are almost apologetic about introducing new ones. The interpretation of neutral model analysis results is no exception to this rule since several hypotheses have emerged to explain the conformity with, or the deviation from, the neutral model predictions.

According to Warwick \& Gee (1984), when meiofaunal population densities are low (due to predation or to sediment disturbance by macrofauna), competitive equilibrium is not approached and therefore diversity is maintained at high levels. Data from the present study do not support this hypothesis in the context of macrofaunal populations since the most densely populated stations were consistently found to be close to the neutral model predictions regardless of the method used to compute the $V$ statistic (individual replicates, average or pooled), while the deeper stations, where the macrofaunal abundance was rather low, seemed to deviate to a larger extent. It has been shown (Karakassis 1991) that in the continental shelf of Crete, the shallow depth zone $(70 \mathrm{~m})$ can be considered as an ecotone since above this depth wave action has a significant impact on the marine sediments, removing the finer particles and reducing the particulate organic material (POM) available to macrofauna, while in the deeper zones $(100$ to $190 \mathrm{~m})$ there is a further decrease in POM with distance from the coast. This ecotone zone is characterised by maximum biomass and species diversity. Rainer (1981) also found an ecotone point where diversity values were in agreement with neutral model predictions while other assemblages, where biological accommodation was expected to be more pronounced, presented reduced diversity. His hypothesis-that adaptations in the species of a community to moderate degrees of short-term environmental stress protect the community against further stress and consequently seasonal fluctuations will be small in such a community - could better explain the patterns observed in our data.

The results of the present paper do not support the opinion that the neutral model is a size-independent method. On the contrary, large samples seem to deviate significantly almost consistently from neutrality.

In each of the stations some of the replicates gave a $V$ statistic value close to neutrality while others presented significantly lower values. In this context the $V$ statistic was found to be the least repeatable descriptor of community structure. Two alternative explanations emerge from this aspect: either neutral model analysis is not an extremely reliable tool or the scale of the disturbance is rather small and therefore this andysis may indeed be a valuable tool for the analysis of patterns within the community. This dilemma is not an easy one to resolve, since it could be expected that other symptoms of disturbance would be also apparent in cases where very low $V$ values are obtained. These sorts of symptoms were not recorded in our study either with respect to physical and chemical parameters or with respect to the faunal data.

The neutral model should be used with caution, especially in cases of ecological monitoring where the number of samples is usually a compromise between accuracy and cost. A minimal number of samples may not accurately represent the community since the values obtained from a small number of samples might be seriously biased

Acknowledgements. Thanks are due to the captain and crew of the RV 'Philia' and the taxonomists W. Plaiti, K. N. Papadopoulou and $\mathrm{K}$. Dounas for the analyses of samples Financial support for the study of the Cretan shelf was provided by the NATO Scientific Affairs Division as part of SFS FISHECO Project, without which the study could not have taken place.

\section{LITERATURE CITED}

Armbruster WS, Edwards ME, Debevec EM (1994) Floral character displacement generates assemblage structure of western Australian triggerplants (Stylidium). Ecology 75: $315-329$

Cale WG, Henebry GM, Yeakley JA (1989) Inferring process from pattern in natural communities. BioSci 39:600-605

Capone TA, Kushlan JA (1991) Fish community structure in dry-season stream pools. Ecology 72:983-992

Caswell H (1976) Community structure: a neutral model analysis. Ecol Monogr 46:327-354

Caswell H (1983) Reply to a comment by Ugland and Gray. Ecology 64:605-606 
Clarke KR (1990) Comparisons of dominance curves. J Exp Mar Biol Ecol 138:143-157

Cornell HV, Lawton JH (1992) Species interactions, local and regional processes, and limits to the richness of ecological communities: a theoretical perspective. J Anim Ecol 61 $1-12$

Garcia CB, Salzwedel H (1991) Structure of soft-bottom macrobenthos in shallow areas off the Caribbean coast of Colombia: introducing a new analysis strategy. In: Elliott M, Ducrotoy JP (eds) Estuaries and coasts: spatial and temporal intercomparisons. Olsen \& Olsen, Fredensborg, p 239-250

Goldman N, Lambshead PJD (1989) Optimization of the Ewens/Caswell neutral model program for community diversity analysis. Mar Ecol Prog Ser 50:255-261

Hill MO (1973) Diversity and evenness: a unifying notation and its consequences. Ecology 54:427-431

Hughes RG (1986) Theories and models of species abundance. Am Nat 128:879-899

Karakassis I (1991) Contribution to the study of the benthic ecosystem of the continental shelf of Crete. PhD thesis, University of Crete, Heraklion

Krebs CJ (1989) Ecological methodology. Harper \& Row Publishers, New York

Lambshead PJD (1986) Sub-catastrophic sewage and industrial waste contamination as revealed by marine nematode faunal analysis. Mar Ecol Prog Ser 29:247-260

Lambshead PJD, Platt HM (1988) Analysing disturbance with the Ewens/Caswell neutral model: theoretical review and practical assessment. Mar Ecol Prog Ser 43:31-41

Loehle C (1987) Hypothesis testing in ecology: physiological aspects and the importance of theory maturation. $Q$ Rev Biol 62:397-409

Margalef DR (1958) Information theory in ecology. Gen Syst 3:36-71

McIntosh RP (1995) H. A. Gleason's 'individualistic concept' and theory of animal communities: a continuing controversy. Biol Rev 70:317-357

This article was submitted to the editor
Palmer MW (1994) Variation in species richness: towards a unification of hypotheses. Folia Geobot Phytotaxon 29: $511-530$

Pielou EC (1969) An introduction to mathematical ecology. Wiley, New York

Platt HM, Lambshead PJD (1985) Neutral model analysis of patterns of marine benthic species diversity. Mar Ecol Prog Ser 24:75-81

Rainer $S$ (1981) Temporal patterns in the structure of macrobenthic communities of an Australian estuary. Estuar Coast Shelf Sci 13:597-620

Rapport DJ, Regier HA, Hutchinson TC (1985) Ecosystem behavior under stress. Am Nat 125(5):617-640

Shannon CE, Weaver N (1949) The mathematical theory of communication. University of Illinois Press, Urbana

Simpson EH (1949) Measurement of diversity. Nature 163:688

Smith DA, Simpson RD (1992) Monitoring the shallow sublittoral using the fauna of kelp (Ecklonia radiata) holdfasts. Mar Pollut Bull 24:46-52

Tokeshi M (1993) Species abundance patterns and community structure. Adv Ecol Res 24:111-186

Turner MG (1989) Landscape ecology: the effect of pattern on process. A Rev Ecol Syst 20:171-197

Turner MG, Gardner RH, Dale VH, O'Neill RV (1989) Predicting the spread of disturbance across heterogeneous landscapes. Oikos 55:121-129

Ugland KI, Gray JS (1983) Reanalysis of Caswell's neutral models. Ecology 64(3):603-605

Warwick RM (1993) Environmental impact studies on marine communities: pragmatical considerations. Aust J Ecol 18: 63-80

Warwick RM. Gee JM (1984) Community structure of estuarine meiobenthos. Mar Ecol Prog Ser 18:97-111

Warwick RM, Platt HM, Clarke KR, Agard J, Gobin J (1990) Analysis of macrobenthic and meiobenthic community structure in relation to pollution and disturbance in Hamilton Bay, Bermuda. J Exp Mar Biol Ecol 138: $119-142$

Manuscript first received: August 3, 1995 Revised version accepted: March 5, 1996 